\title{
Forecast and Disaster Cause Analysis of Tropical Storm Damrey into the Gulf of Bohai
}

\author{
Zhiming Yu， Siyao Wang， Xiaodong Zhang \\ The Tangshan City Meteorological Bureau, Tangshan Hebei 063000, China

\section{进入渤海湾的热带风暴 “达维” 预报 及灾害成因分析}

于志明, 王驱鹞, 张晓东

唐山市气象局, 河北唐山, 063000

\begin{abstract}
Based on the data of FY-2E infrared cloud image, radar, micaps3.1, island observation station, large buoy, and numerical weather forecasting products, effects of tropical storm Damrey in 2012 on Tangshan were analyzed, forecast and disaster cause of tropical storm Damrey were also analyzed. The results show that the mesoscale low pressure system, going into the west area of $38^{\circ} \mathrm{N}, 121^{\circ} \mathrm{E}$, will move toward north fast along the 588 line of the subtropical high. When more than $39^{\circ} \mathrm{N}$, the system will turn to northeast by the effect of westerlies, and move faster. Double effect of ultra low level southeast jet on the sea was obvious, not only is the power factor but also the water vapor factor. Strong precipitation and wind of Damrey appears at the point, which is the inflection point of the line 586 of the subtropical high on 500hpa upper weather map. Leting County flooded seriously because of the 5 consecutive rainstorms and the storm surge of Damrey.
\end{abstract}

Keywords: Damrey; Forecast; Disaster; Storm surge

\begin{abstract}
摘要
利用 FY-2E 红外云图、雷达、micaps3.1、 海岛站、大浮标站及数值产品检验资料, 分析了 2012 年进入渤海的热带风暴 “达 维” 对河北省唐山市的影响, 对 “达维” 的预报和造成灾害的成因进行了研究。结 果表明: 进入 $38^{\circ} \mathrm{N}, 121^{\circ} \mathrm{E}$ 以西的中尺度 低压系统, 将会沿副高 588 线边缘快速北 上, 超过 $39^{\circ} \mathrm{N}$ 时, 在西风带作用下移向 转为东北, 移速加快; “达维” 进入渤海后 海区超低空东南急流 “双重效应” 明显, 既是动力因子又是水汽短时输送因子, 产 生的强降水位于 500 百帕高空图 “588 脊 线” 拐点处; 前期连续出现的五次暴雨和 “达维” 产生的风暴潮使乐亭县出现了严 重的内涝灾害。
\end{abstract}

关键字：达维；预报；灾害；风暴潮

1. 引言

热带气旋的破坏力主要是由暴雨、强 风和风暴潮三个因素引起的, 给经过地区 的工农业生产、交通运输和人民生命财产 安全造成严重威胁和极大损失, 一直被广 大气象工作者 ${ }^{[1,2]}$ 所关注。近年来, 许多 
学者对如何避免和减轻的自然灾害的损失 进行了研究与探讨 ${ }^{[3.4]}$. 科研部门曾开展过 大规模的热带气旋外场 ${ }^{[5,6]}$ 监测及数值模 拟 ${ }^{[7]}$ 试验, 对热带气旋的运动突变、结 构、强度变化和热带气旋暴雨 ${ }^{[9}{ }^{90]}$ 等方面 进行了一系列 ${ }^{[11,12]}$ 的研究, 一些科研成果 在多次热带气旋预报中得到了较好的应 用。但对于北上进入渤海一线的热带气旋 路径偏差 ${ }^{[13]}$ 、预报指标 ${ }^{[14 、 15]}$ 及灾害成因 ${ }^{[161}$ 等仍处于探讨阶段。“达维” 是 1949 年以 后登陆我国长江以北地区最强的热带气 旋, 唐山市气象台对 “达维” 进行了系统 的分析, 做出了较准确的预报, 进行了较 成功的预警服务。在前期连续出现 5 次暴 雨的背景下, 受 “达维” 造成的大风、强 降水和农历十五天文大潮影响, 唐山南部 沿海的乐亭县仍出现了严重的内涝灾害。

本文以河北省唐山市为例, 针对 2012 年进入渤海海域的热带风暴 “达维” 的预 报着眼点、难点和导致唐山南部沿海乐亭 县出现严重内涝灾害的成因进行了分析。 以积累沿渤海北上热带气旋的暴雨和风暴 潮的预报指标, 为抵御热带气旋灾害提供 参考。

\section{2. “达维” 概况及对唐山的影响}

2.1 “达维” 概况

2012 年第 10 号热带气旋 “达维” 7

月 28 日 20 时生成, 7 月 31 日 8 时加强为 强热带风暴, 8 月 1 日 8 时加强为台风, 下午进入黄海, 强度继续加强, 于 8 月 2 日 21 时 30 分前后在江苏省响水县陈家港 镇沿海登陆。之后, “达维”于 8 月 3 日 1 时在江苏省连云港市减弱为强热带风

暴, 9 时在山东沂源县减弱为热带风暴。 4 日凌晨 2 时进入渤海, 之后强度继续减 弱。上午 8 时, 热带风暴 “达维” 在河北 省东北部近海减弱为热带低压, 11 时停止 编号。

2.2 唐山实况监测资料

受 “达维” 影响, 3 日白天到 4 日上 午, 唐山有 67 个乡镇雨量超过 100 毫米, 雨量从西北至东南向呈梯度递增分布, 有
15 个乡镇雨量超过 200 毫米, 有 4 个乡镇 雨量超过 250 毫米, 过程最大降水量出现 在乐亭县王滩镇为 279 毫米。

\section{3 灾情概况}

河北省唐山市的乐亭县降水量最大, 受 灾最重, 8 月 3 日 7 时至 4 日 5 时乐亭全县 普降大暴雨到特大暴雨, 乐亭县出现严重内 涝, 据民政部门统计, “达维” 造成全县 531 个村受灾, 倒塌房屋 6000 多间, 90\%的沿海 养殖户 “血本无归”。经济损失 42 亿元。

\section{3. 预报着眼点和难点}

3.1 预报着眼点

\subsection{1 “达维” 路径分析}

2005 年到 2012 年近 8 年中, 曾有三 次热带气旋进入黄渤海区域, 即 2005 年

“麦莎”、2011 年 “梅花” 及 “米雷”, 进 入渤海后的 “达维” 与前 3 次热带气旋相 比是路径最偏西的一次。对 “达维” 同样 出现了 0-72 小时日本、 $\mathrm{EC} / \mathrm{T} 639$ 预报路径 及中央台、省台预报意见存在分歧情况, 预报结论不断被订正。唐山市气象台参考 前 5 次暴雨落区形势场 (图 1), 实时对比 日本、 $\mathrm{EC} / \mathrm{T} 639$ 、中央台数值产品检验资料, 查阅进入黄渤海区域的 “麦莎”、“米雷” 及 “梅花” 的环流形式和云图特征。得出 结论: 进入 $38^{\circ} \mathrm{N}, 121^{\circ} \mathrm{E}$ 以西的中尺度低 压系统, 将会沿副高 588 线边缘快速北上, 超过 $39^{\circ} \mathrm{N}$ 时, 在西风带作用下移向转为 东北, 移速加快。“达维” 符合以上特征, 将影响唐山东南部沿海地区。

\subsection{2 动力和水汽分析}

通过分析副高 12-24 小时 588 线位置, 925 百帕水平风场特征（浴旋型有利于海 岸带大暴雨); 卫星监测水平尺度和雷达监 测高度 (大于 9 公里)。1000-925 百帕存 在明显低空东南风急流, 海区超低空东南 急流 “双重效应” 明显, 既是动力因子又 是水汽短时输送因子, 强的东南急流配合 宽而深厚的水汽输送带及垂直向的水汽输 送, 为 “达维” 提供了有利的动力和水汽 条件。 
Risk Analysis and Crisis Response in Big Data Era (RAC-16)
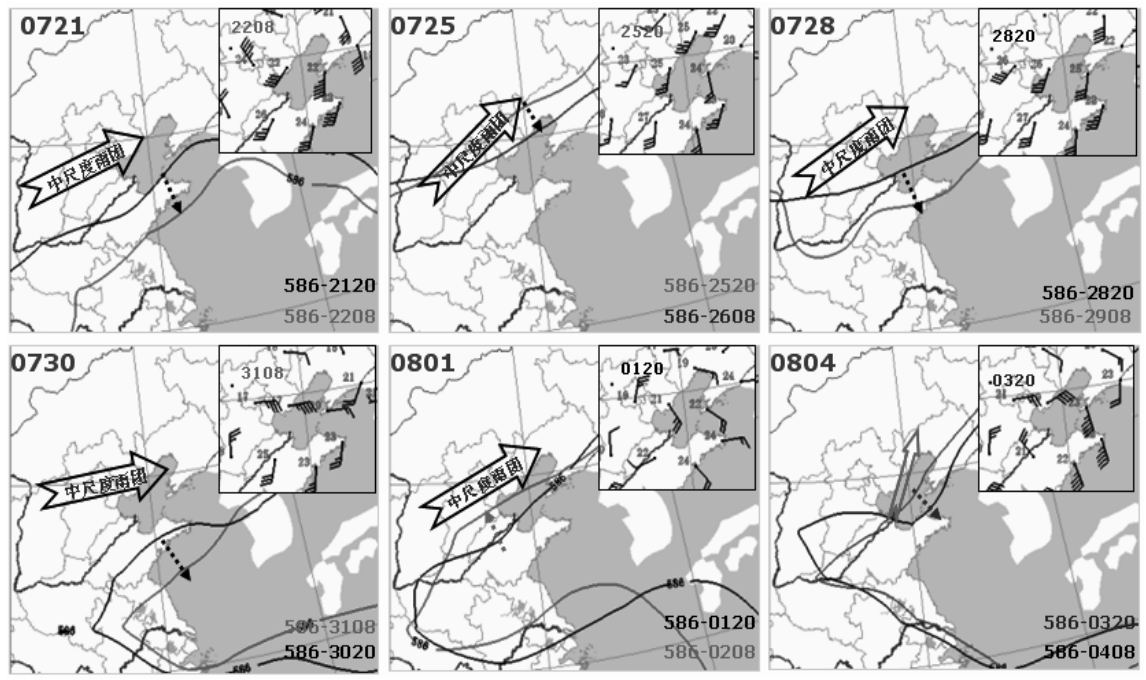

图 1 六次强降水过程 500 百帕 “586 线” 12 小时动态与 925 百帕风场叠加图

\section{1 .3 动力和水汽分析}

通过实时调阅 FY-2E 红外云图与实况 雨量叠加、雷达拼图、海岛站等, 对比最 新热带气旋路径预报、6 小时降水落区 (图
2)、云模式冰晶 (图 3)、逐小时红外云顶 $\mathrm{TBB}$ 分布 (图 4) 等资料, 得出: 强降水区 位于 500 百帕高空图 “586 脊线” (500 百 帕高空图 584 线和 588 线之间增划的等值

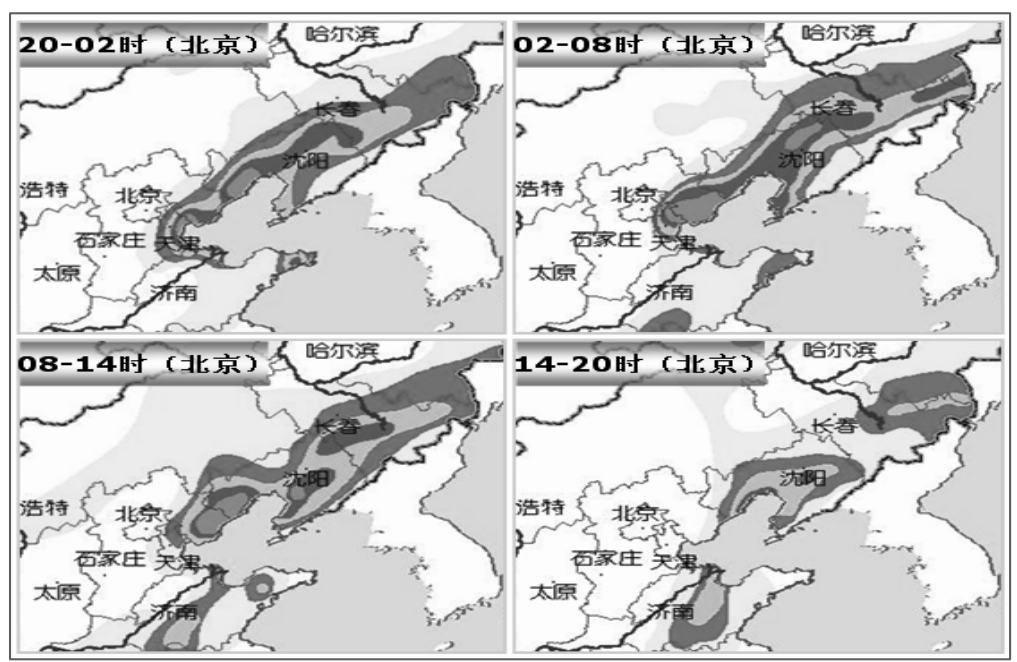

图 2 中央台 2012 年 8 月 3 日 16 时 (北京时) “达维” 热带气旋 6 小时雨量预报 


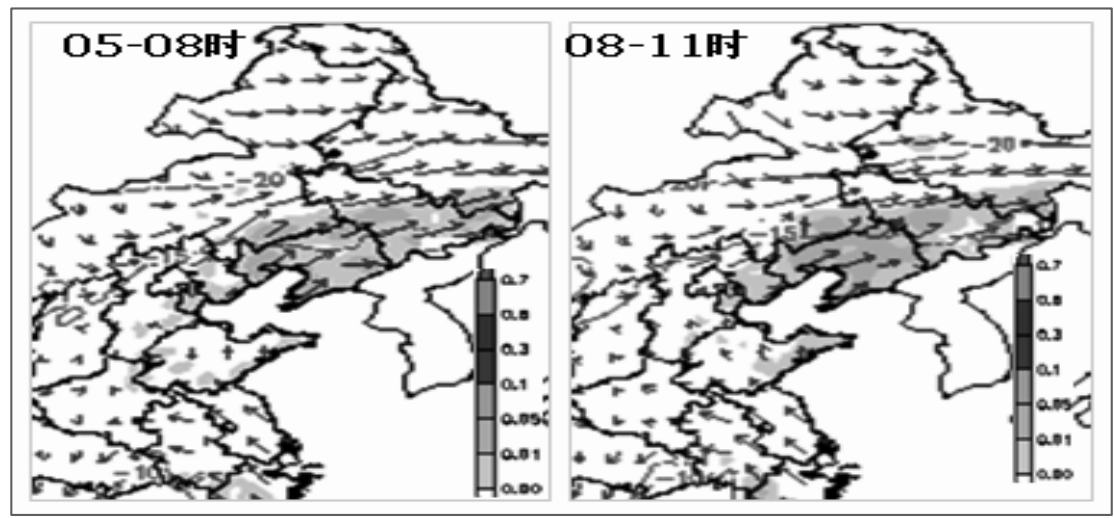

图 3 中央台 2012 年 8 月 4 日 05-11 时 (北京时) 云模式 $400 \mathrm{hPa}$ 冰晶数值产品

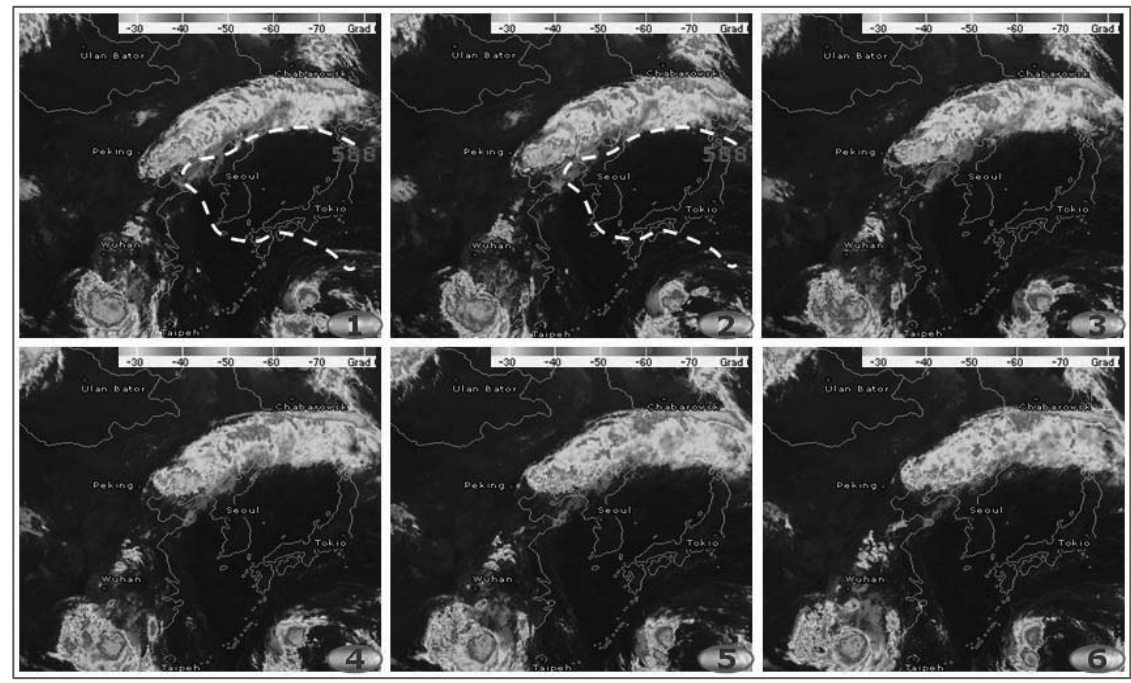

图 4 FY-2E 红外云图 2012 年 8 月 4 日 1-6 时 (北京时) “达维” 云系与副高配置

线）拐点处。进入渤海的 “达维” 降水过 程分为两个时段: 8 月 3 日 20 时之前受热 带气旋云系间接影响, 主要为副热带高压 外围降水, 20 时之后受进入渤海的“达维” 主体系统云系影响。

3.2 预报难点

“达维” 72 小时路径不确定; 24 小时 次天气尺度 “达维” 浴旋状云系在进入渤 海后加强的依据不充分, 单站大暴雨中心 不好确定, 把它视为 “副高边缘中尺度浴 旋类” 降水量小于 180 毫米, 14-20 时山 东实况最大为 104 毫米; “双热带气旋直接
或间接效应” 对系统移速及强度变化不确 定, 事实上比 “副高边缘中尺度涡旋类” 移动速度慢 6-8 小时。3 日 08 时 “达维” 受副高 588 线边缘带状云系 (SE 引导气流) “汼制” 并从菲律宾东部海区热带云团中 补充能量（图 5); 20 时副高西伸 “苏拉” 北部中尺度云团发展构成径向超天气尺度 云带, 但在西风带和副高急流引导下, 加 快 $\mathrm{NE}$ 向移速脱离 “苏拉” 双热带气旋效应 的影响, 转为 “副高边缘中尺度云团暴雨 类型”。 
Risk Analysis and Crisis Response in Big Data Era (RAC-16)

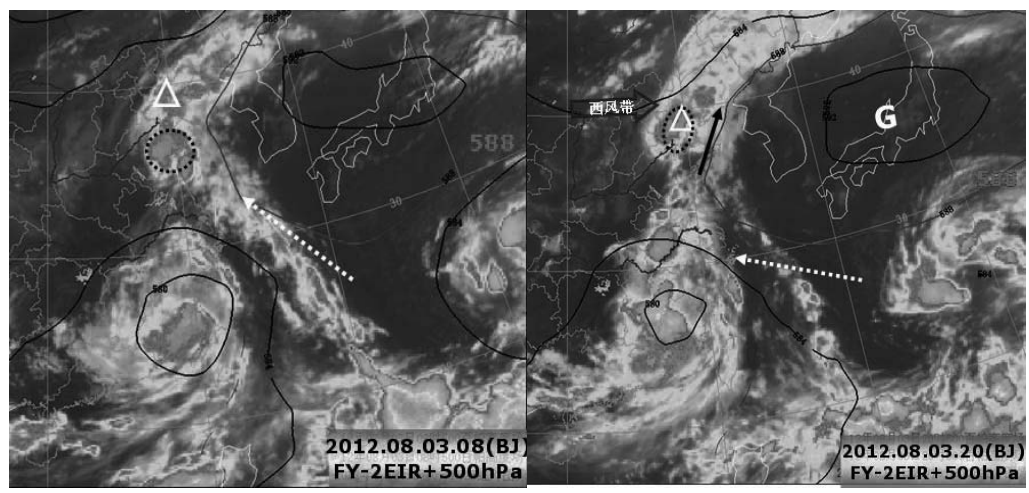

图 5 “达维” FY-2E 红外云图 12 小时对比及 500 百帕副高叠加分析图

\section{4. 灾害成因分析}

4. 1 大风造成的增水影响

8 月 2 日 08 时一 3 日 08 时，期间 “达 维” 位于黄海中南部, 黄海中部受 “达维” 影响东南大风明显, 黄海北部受偏东风控 制，导致黄海中部大量水体不断向黄海北 部涌入, 经渤海海峡进入渤海, 同时 1209 号热带气旋“苏拉”位于东海南部, 受“苏 拉” 东北部东到东南大风影响, 使东海水 体不断向黄海涌入; 两者共同作用，使渤 海水位不断升高, 造成较大的增水。3 日 白天随着 “达维” 在山东半岛继续北上, 渤海中西部东北风不断加大，最大风力达 8-9 级阵风 $10-11$ 级, 风增水明显; 前
期涌入渤海的水体无法排出, 继续向渤海 西部输送, 增水值进一步加大, 同时受“苏 拉” 的影响从东海南部到黄海中部维持较 大的东南风，使东海至黄海中部的水体仍 向北涌入。3 日夜间至 4 日凌晨 “达维” 从莱州湾进入渤海, 渤海湾内部为东北大 风影响 (图 6), 使渤海湾唐山海域增水呈 持续增大的趋势。

天津塘沽闸下验潮站观测: 3 日 00 时 增水值为 $116 \mathrm{~cm}, 3$ 日 23 时增水值达到 $137 \mathrm{~cm}, 4$ 日 01 时增水达最大值 $140 \mathrm{~cm}$ 。 乐亭县距天津塘沽的直线距离约 150 公 里, 以上天津塘沽的增水资料可作为乐亭 海域增水的参考。

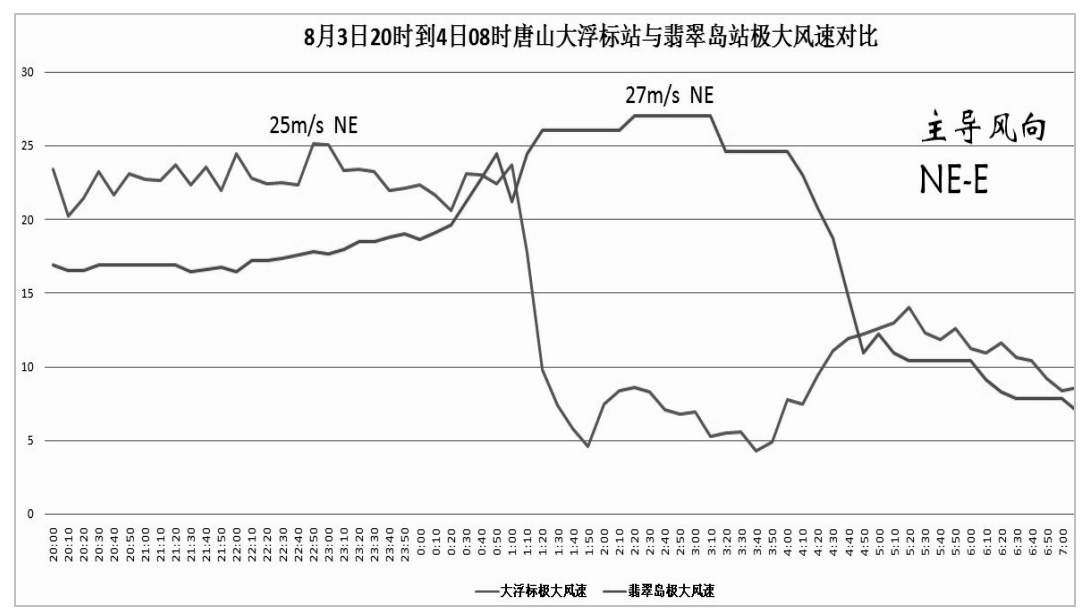

图 62012 年 8 月 3 日 20 时-4 日 08 时 (北京) 唐山大浮标站与秦皇岛翡翠岛站风速(单位: $\mathrm{m} / \mathrm{s}$ ) 


\section{2 连续六次强降水影响}

2012 年 7 月 21 日-8 月 4 日, 唐山连 续出现 6 次强降水天气过程, 平均降水量 大于 400 毫米。3 日, 唐山上游的大黑汀、 潘家口等水库库容压力剧增, 水库加大泄 洪, 使流经乐亭县的滦河和小青河水位迅 速上涨。

\section{3 天文大潮影响}

乐亭县地势低平, 西北高、东南低, 东南部沿海海拔高度不足 1 米, 8 月 3 日 恰逢阴历六月十六天文大潮期 (3 日 17 时 天津塘沽闸下最高潮位达 $507 \mathrm{~cm}$ ), 高潮 位和大风引起的渤海湾增水导致渤海海平 面上涨, 连续强降水和上游水库放水导致 河水猛涨, 使乐亭境内㴒河和小青河入海 口水面低于海平面, 洪水长时间难以退却, 海水倒灌, 河水漫过堤坝。

\section{5. 结论}

（1）进入 $38^{\circ} \mathrm{N}, 121^{\circ} \mathrm{E}$ 以西的中尺 度低压系统, 将会沿副高 588 线边缘快速 北上, 超过 $39^{\circ} \mathrm{N}$ 时, 在西风带作用下移 向转为东北, 移速加快。“达维” 是近 8 年进入黄渤海地区位置最偏西的热带气 旋。

（2） “达维” 进入渤海后海区超低空 东南急流 “双重效应” 明显, 既是动力因 子又是水汽短时输送因子, 产生的强降水 区位于 500 百帕高空图 “586 脊线” 拐点 处。强降水过程分为两个时段: 8 月 3 日 20 时之前受热带气旋云系间接影响, 主要 为副热带高压外围降水, 20 时之后受进入 渤海的 “达维” 主体系统云系影响。

（3）因风暴潮的增水效应导致的海平 面升高, 连续强降水和上游水库放水导致 河水上涨, 河水入海口低于海平面使洪水 长时间难以退却, 风雨潮三碰头导致乐亭 县出现了严重的内涝灾害。

\section{参考文献}

[1] 方宗义, 许健民, 赵凤生. 中国气象卫星和 卫星气象研究的回顾和发展.气象学 报,2004,62(5):550-560.

[2] 陈联寿. 热带气旋研究和业务预报技术的 发展. 应用气象学报 2006, 17(6):
672-681.

[3] Li Yuhong Shi Lian,,Wang Jiazhuo,et al. Pluvial Flooding Risk Analysis and the Solutions to Risk Mitigation for Dangyang City in China. Journal of Risk Analysis and Crisis Response, Vol. 5, No. 2 (July 2015), 107-119

[4] Li shuaijie,Xie Yingxia,Cheng Xiaotao, et al.. Utilization of Flood Simulation Technique in Urban Flood Warning - A Case Study on Fuzhou . Journal of Risk Analysis and Crisis Response, Vol. 5, No. 2 (July 2015), 120-128

[5] 张光智,徐祥德. 采用外场观测试验资料 对登陆台风"黄蜂"的风场及湍流特征 的观测研究. 应用气象学报, 2004, 15(s): 110-115

[6] 毕宝贵,林建,徐晶.气象卫星资料在天气 预报分析业务中的应用.气 象,2004,30(11):19-23.

[7] 李燕, 黄振. 对"麦莎"路径及造成黄渤海 域大风浪的数值模拟.气象科 技,2007,35(2): 175-179.

[8] 刘学刚,李庆宝,张金艳.近年来引发青岛 暴雨的台风特征分析.气象, 2011, 37(9): 1091-1099.

[9] 刘健, 张文建, 朱元竞, 等.中尺度强暴雨云 团云特征的多种卫星资料综合分析. 应 用气象学报, $2007,18(2): 158-164$

[10] 何立富,尹洁,陈涛,等.0509 号台风麦莎 的结构与外围暴雨分布特征.气象, 2006, 32(3):93-100.

[11]张玲.2010 年西北太平洋和南海台风特 点及其与冷空气相关的预报难点分析. 天气预报技术总结专刊, 2011，3(6): 16-24.

[12] 许映龙, 韩桂荣, 麻素红.1109 号超强台 风“梅花”预报误差分析及思考.气 象,2011,37(10):1196-1205.

[13] 钱燕珍,张寒. 台风森拉克路径特征与预 报难点分析.气象,2004,30(9): 19-23.

[14] 黎惠金,覃昌柳,韦江红.一次全区性较 强降水空报的重大预报失误过程分析. 气象, 2005,31(1):33-36.

[15] 王焕毅,杨萌,魏海宁, 等. 台风 “达维” 路 径变化及物理量诊断分析. 中国农学通 报,2014,30(8):256-261.

[16] 王亚男,王庆元.1210 号台风大风和渤海 湾天津沿岸风暴潮分析. 海洋预 报,2013,30(6):7-12. 